\title{
The Role of Split Costochondral Graft in the Restoration of Nasal Dorsum in Post-Traumatic Nasal Deformities
}

\author{
TAREK M. ELBANOBY, M.D.
}

The Department of Plastic and Burn Surgery, Faculty of Medicine, Al-Azhar University

\begin{abstract}
Introduction: Rhinoplasty in the treatment of traumatic nasal deformity remains one of the most challenging problems for surgeons. Reconstruction of the nasal osseocartilaginous framework is the foundation of successful rhinoplasty. In this article, we present our experience in restoration of the dorsum of the nose in post-traumatic nasal deformities, by carved insitu split costochondral graft as a new technique to restore the missing part of the nose.
\end{abstract}

Patients and Methods: From April 2013 to May 2016, 13 patients, including nine males and four females underwent augmentation rhinoplasty for the correction of the posttraumatic nasal deformity. Patients in need of soft tissue reconstruction were excluded from this study. The nature of nasal deformities varied between saddle nose, a crooked nose or combined. The nasal dorsum was restored using the split costochondral graft. The mean follow-up period after the surgery was 22 months. Patients' satisfaction evaluation was obtained, and the results were analyzed and reported.

Results: A total of 13 rib graft rhinoplasties were performed in the three-year review period. The mean duration of clinical follow-up was 22 months. None of the grafts warped. None of the patients had lost dorsal projection; only one patient has lost the columellar strut secondary to infection, two of the patients developed hypertrophic scars, and two of 13 patients $(26 \%)$ had revision surgery for minor cosmetic revision.

Conclusion: The fundamental strength of the osseocartilaginous rib graft lies in replacing like with like. In-situ splitting of the costochondral graft provides a safe and efficient method to restore the nasal dorsum. A chimeric bony and cartilaginous graft allows for bone integration with the nasal dorsum, preventing mobilization, and allows for subtle sculpting of the cartilaginous nasal tip.

Key Words: Split costochondral flap - Nasal dorsum - Posttraumatic - Nasal deformity.

\section{INTRODUCTION}

Nasal deformity following trauma represents one of the most common reasons that patients seek septorhinoplasty. Such nasal deformity is considered a cripple to patient's life. Restoration of the nasal osseocartilaginous framework is the foundation of successful nasal restoration [1,2]. Identifying structural weaknesses that contribute to the unac- ceptable nasal appearance which necessitates support and reconstruction of the nasal osseocartilaginous framework against the Skin Soft Tissue Envelope results in an aesthetic and functional correction $[3,4]$.

In this article, we present our experience in restoration of the dorsum of the nose of such major nasal deformities, by carved in-situ split costochondral graft as a new technique to restore the missing part of the nose.

\section{PATIENTS AND METHODS}

We retrospectively analyzed data from 13 patients who underwent rhinoplasty and restoration of the dorsum by using in-situ split costochondral graft between April 2013 to May 2016. The study population consisted of ( 4 females and nine males) ages 18 to 52 years (mean, 32 years). Written informed consent was obtained from all patients. All the patients had breathing problems of varying degrees and complained about their facial appearances. All the patients had a variable degree of facial deficiency. Patients in need of soft tissue reconstruction were excluded from this study. Demographic data of the patients collected in Table (1) and the nature of nasal deformities varied between saddle nose, a crooked nose or combined. The nasal dorsum was restored using the split costochondral graft. The mean follow-up period after the surgery was 22 months (range, 12-36 months).

We obtained patients' satisfaction evaluation regarding the improvement of aesthetic and functional aspects, and the classifications were excellent, good, fair, or poor. Postoperative records were reviewed to assess surgical morbidity, including graft resorption, postoperative infection, visible graft contour, fracture due to trauma, warping, seroma, pneumothorax, keloid formation, and persistent pain at the donor site (Table 1). 
Table (1): Demographic data of the patients with an overview of the satisfaction rate and additional procedures.

\begin{tabular}{|c|c|c|c|c|c|c|c|}
\hline & $\begin{array}{l}\text { Age } \\
\text { (years) }\end{array}$ & Six & Deformity & Satisfaction & Complication & $\begin{array}{l}\text { Additional } \\
\text { procedures }\end{array}$ & $\begin{array}{l}\text { Secondary } \\
\text { proceduers }\end{array}$ \\
\hline 1 & 49 & Female & Saddle nose & Excellent & & & \\
\hline 2 & 24 & Male & Crooked nose & Excellent & & Spreader graft & \\
\hline 3 & 23 & Male & Crooked nose & Excellent & & Spreader graft & \\
\hline 4 & 18 & Male & Combined & Good & $\begin{array}{l}\text { Hypertrophic } \\
\text { scar in the chest }\end{array}$ & Spreader graft & $\begin{array}{l}\text { Camouflaged by } \\
\text { conchal graft }\end{array}$ \\
\hline 5 & 33 & Female & Saddle nose & Excellent & & & \\
\hline 6 & 21 & Male & Crooked nose & Good & & Spreader graft & \\
\hline 7 & 42 & Male & Saddle nose & Excellent & & & \\
\hline 8 & 18 & Female & Saddle nose & Fair & $\begin{array}{l}\text { Infection in the } \\
\text { reciepient site }\end{array}$ & & $\begin{array}{l}\text { Columellar strut } \\
\text { from the banked } \\
\text { cartilge }\end{array}$ \\
\hline 9 & 22 & Male & Combined & Good & $\begin{array}{l}\text { Hypertrophic } \\
\text { scar in the chest }\end{array}$ & Spreader graft & \\
\hline 10 & 36 & Male & Saddle nose & Good & & & \\
\hline 11 & 27 & Male & Combined & Excellent & & Spreader graft & \\
\hline 12 & 29 & Male & Crooked nose & Excellent & & Spreader graft & \\
\hline 13 & 52 & Female & Saddle nose & Excellent & & & \\
\hline
\end{tabular}

Operative technique:

Marking:

All the operations were performed with the patient under general anesthesia. After measuring the distance between the frontonasal angle and the nasal tip, Autogenous in situ split costochondral grafts were obtained from the fifth, sixth or seventh rib from the patient's left side through a 3 to $4 \mathrm{~cm}$ transverse incision. In female patients, the incision was marked approximately $5 \mathrm{~mm}$ above the inframammary fold.

\section{Harvesting of the costal cartilage and rib graft:}

The local anesthetic solution consisted of $1 \%$ lidocaine with 1:200,000 epineph-rine was administered at the incision line, following skin incision, the subcu-taneous tissue was dissected using electrocautery, the external oblique, and rectus abdominis muscles are divided. The anterior surface of the fifth, sixth or seventh rib and costal cartilage is exposed, and the periosteum and perichondrium are dissected and elevated over the superior and inferior edges of the rib. Along the superior and inferior cortexes, sharp osteotome is used to separate the outer surface of the rib (Fig. 1). After that, the cartilage is incised in partial thickness. The depth of the incisions depends on the thickness of the cartilage graft layers required. The posterior segment of the costal cartilage with its perichondrium is left intact.

The anesthesia ventilation circuit is then disconnected, and the lungs are allowed to rest without positive pressure ventilation. Water is then used to fill the wound, the circuit reconnected, and positive pressure at $30 \mathrm{~cm}$ of $\mathrm{H}_{2} \mathrm{O}$ held to ensure that there is no pleural leak.

The cartilage grafts for the nasal dorsum and columellar strut were shaped and curved with a surgical knife from the harvested cartilage grafts. A 14-gauge angiocath catheter (18 x $1.3 \times 45 \mathrm{~mm})$ was inserted through the skin and placed in the subperichondrial space on the donor site. For 2 to 3 days, three times a day, local anesthesia solution was injected into the subperichondrial space.

The wound is then closed in layers, closing the periosteal envelope where possible, reapproximating the muscle/fascia, the excess cartilge is banked in a subcutanous pocket, deep dermis, and finally skin.

\section{RESULTS}

A total of 13 rib graft rhinoplasties were performed in the three-year review period. All patients who had dorsal onlay rib grafts and columellar strut cartilage graft, The mean duration of clinical follow-up were 22 months. None of the grafts warped. None of the patients had lost dorsal projection; only one patient has lost the columellar strut secondary to infection, two of the patients developed hypertrophic scars, and two of 13 patients $(26 \%)$ had revision surgery for minor cosmetic revision. There were no seroma, pneumothorax, keloid formation, or persistent pain at the donor site. Results of the questionnaire are assembled in Table (1) and Fig. (4). 

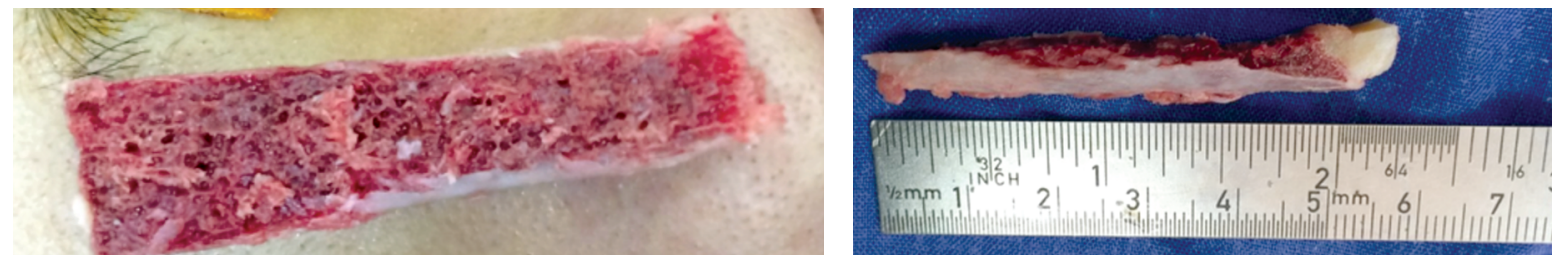

Fig. (1): Six-centimeter split rib segment harvested from left chest. Notice that the tip of the graft contains its cartiliginous part attached.
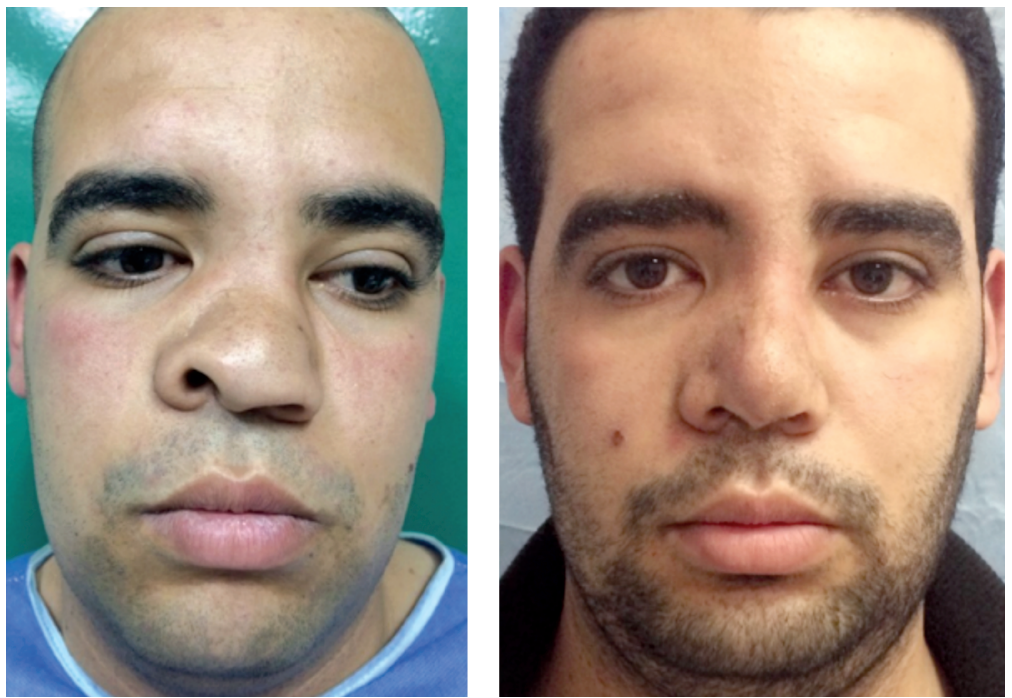

Fig. (2): Preoperative (left) and 3-month postoperative (right) photographs of a 23-yearold man with a deviated nose and a tip ptosis. The patient underwent rhinoplasty involving a dorsal onlay graft and columellar strut graft.
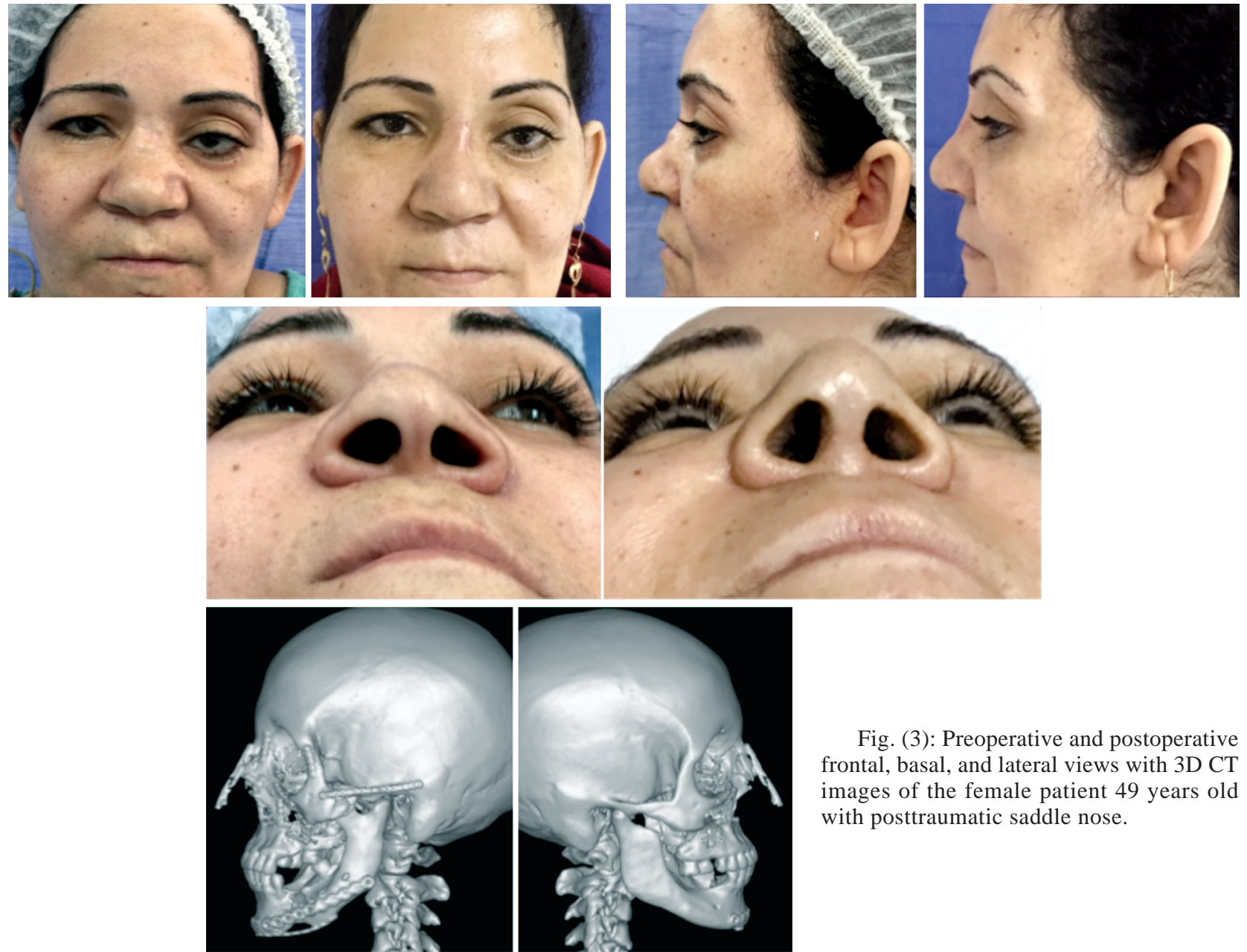

Fig. (3): Preoperative and postoperative frontal, basal, and lateral views with 3D CT images of the female patient 49 years old with posttraumatic saddle nose. 


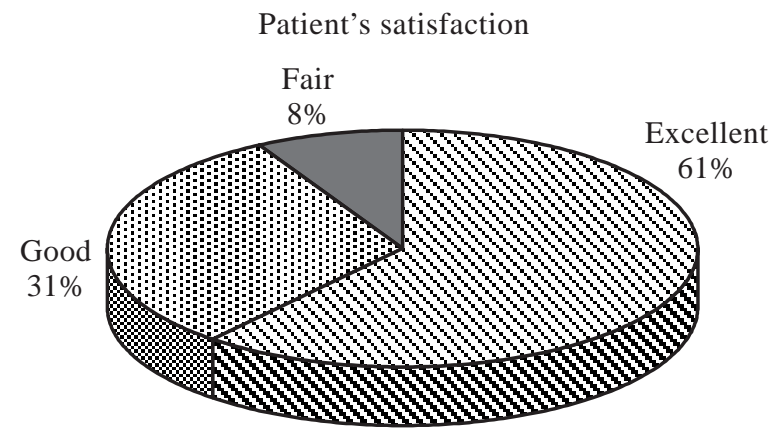

Fig. (4): Pie chart demonstrates percentage of patient's satisfaction.

\section{DISCUSSION}

Correction of posttraumatic nasal deformities requires attention to numerous defects and anatomical scenarios. One of the main goals of the rhinoplasty is to restore the structural support of the dorsum of the nose and to replace lost soft tissue volume [5]. High-energy facial trauma results in comminuted facial bone fractures with or without open injuries to the soft tissue. The saddle nose deformity represents one of the most dreaded complications of nasal trauma. Typically, the etiology is one of an untreated septal hematoma becoming infected, forming an abscess and leading to septal cartilage resorption [6]. On the other hand, The initial description of the crooked nose and its surgical management were linked to posttraumatic and congenital deformities [7]. Converse reported that "the deviated or twisted nose is most often of traumatic origin" [8].

To restore the aesthetic profile of the nose after a traumatic nasal deformity, a considerable volume of the graft is often required. Autogenous tissues, such as bone and cartilage, have been the primary choices for nasal reconstruction. The biocompatibility is unsurpassed, and the risk for infection and protrusion is far less as compared with alloplastic materials $[\mathbf{9 , 1 0}]$.

The characteristics of an ideal graft are well documented and include stability over time, malleability, adequate supply, low risk of donor site morbidity, low rate of extrusion and low risk of triggering an immune/inflammatory response $[11,12,13]$.

The purpose of our study was to identify a method of achieving more efficient and permanent correction of the nasal dorsum in severe posttraumatic nasal deformities. In the presented clinical series, the patients had either a presentation of saddle nose, crooked nose or both secondary to trauma. Moreover, these patients often complain about difficult nasal breathing due to the collapse of the sidewalls and the nasal valves.

There are various grafts and implants available to the rhinoplastic surgeon that can be used to restore the volume and structural integrity of the nose. The available biomaterials can be divided into two broad categories: Autografts, which are derived from the patient and include cartilage, bone, fascia, and dermis; and homografts, which are derived from tissues donated by members of the same species and include irradiated cartilage and acellular dermis. Alloplastic implants are synthetic implants (biocompatible polymers) with a variety of applications in plastic surgery $[\mathbf{1 4 , 1 5 ]}$.

Several authors have emphasized rib cartilage as the best autologous material available for use in dorsum restoration and as columella strut. Cakmak et al., concluded that autogenous costal cartilage serves as outstanding material for volume filling and support during rhinoplasty [16].

Gerow and Coll obtained excellent results with fragments of costal bone appropriately shaped and joined to form a structure of support for the dorsum, and the columella (known as a "totem pole rib graft") anchored itself by a transversal support in the Naso premaxillary area [17].

Autogenous costochondral osseocartilaginous grafts have been used successfully in augmenting the midfacial, columellar, and septal deficiencies because they maintain their volume over the years with only minimal resorption and are easily sculptured $[18,19,20]$.

The costochondral graft has the disadvantages of an additional incision, visible scarring, postoperative pain, warping, and fixation problems. The resultant scars were unnoticeable in all cases, but care must be taken with patients who have a tendency for hypertrophic scars and keloids [21]. Otsuyanagi et al., reviewed their experience with costal cartilage harvest in 28 patients undergoing rhinoplasty. They reported decreased donor site pain and morbidity with a conservative technique regarding harvest [22]. Our study supports their findings, but we recommend in vitro splitting of the harvested grafts as well as the preservation of the anterior perichondrium and periosteum to aid in cartilage regrowth and to minimize the risk of pneumothorax. 
The fundamental strength of the osseocartilaginous rib graft lies in replacing like with like. When major dorsal augmentation is performed, cartilage or bone grafts are required to masquerade as either bone or cartilage at some point along the dorsum, depending on the graft used. A chimeric bony and cartilaginous graft allows for bony integration with the nasal dorsum, preventing mobilization, and allows for fine sculpting of the cartilaginous nasal tip.

Graft resorption and warping is the foremost graft-related complication in rhinoplasty using autologous costal cartilage [24]. Gibson and Davis [25] used concentric segments of the costochondral graft to decrease interlocking stresses. It has been demonstrated that dynamic composition of proteinpolysaccharides within cartilage produces internal tensile stresses that cause the cartilage to change shape with time [26]. It has been documented that the central portions of the costochondral graft warped less than peripheral portions [27].

During a mean follow-up of 2.5 years, there was no remarkable absorption of the bone in this clinical series. There was no patient with secondary deformities due to cartilage warping either.

\section{Conclusion:}

The fundamental strength of the osseocartilaginous rib graft lies in replacing like with like. Insitu splitting of the costochondral graft provides a safe and efficient method to restore the nasal dorsum A chimeric bony and cartilaginous graft allows for bony integration with the nasal dorsum, preventing mobilization, and allows for subtle sculpting of the cartilaginous nasal tip.

\section{REFERENCES}

1- Sheen J.H. and Sheen A.P.: Aesthetic Rhinoplasty, 2nd Ed. St. Louis: Quality Medical, 1998.

2- Gunter J.P. and Rohrich R.J.: External approach to secondary rhinoplasty. Plast. Reconstr. Surg., 80: 161, 1987.

3- Quatela V.C. and Jacono A.A.: Structural grafting in rhinoplasty. Facial Plast Surg., 18: 223-232. [PubMed: 12524594], 2002.

4- Cochran C.S.: Harvesting Rib Cartilage in Primary and Secondary Rhinoplasty. Clin. Plast. Surg., 43 (1): $195-$ 200, 2016.

5- Toriumi D.M. and Hecht D.A.: Skeletal modifications in rhinoplasty. Facial Plast. Surg. Clin. N. Am., 8: 413-32, 2000 .

6- Alsarraf R. and Murakami C.S.: The saddle nose deformity. Facial Plast Surg. Clin. N. Am., 7: 303-10, 1999.
7- Toriumi D.M. and Watson D.: Innovative surgical management of the crooked nose in rhinoplasty. In: The Dallas Rhinoplasty Symposium Text. St. Louis, MO: Quality Medical Publishing, 2001.

8- Converse J.M.: Corrective surgery of nasal deviations. AMA Arch. Otolaryngol., 52 (5): 671-708, 1950.

9- Chen C.T., Hu T.L., Lai J.B., et al.: Reconstruction of traumatic nasal deformity in Orientals. J. Plast. Reconstr. Aesthet. Surg., 63 (2): 257-64, 2010.

10- Romo T. and Kwak E.S.: Nasal grafts and implants in revision rhinoplasty. Facial Plast Surg. Clin. North Am., 14 (4): 373-387, 2006.

11- Kim D.W. and Toriumi D.M.: Management of posttraumatic nasal deformities. Facial Plastic Surg. Clin. N. Am., 12: 111-132, 2004.

12- Becker D.G.: Complications in rhinoplasty. In: Papel et al., editors. Facial plastic and reconstructive surgery. $3^{\text {rd }}$ ed. New York: Thieme Medical Publishers, p. 639-648, 2009.

13- Young K. and Rowe-Jones J.: Current approaches to septal saddle nose reconstruction using autografts. Curr. Opin. Otolaryngol. Head Neck Surg., 19 (4): 276-282, 2011.

14- Sajjadian A., Rubinstein R. and Naghshineh N.: Current status of grafts and implants in rhinoplasty: part I. Autologous grafts. Plastic and Reconstructive Surgery. Feb., 1; 125 (2): 40e-9e, 2010.

15- Sajjadian A., Naghshineh N. and Rubinstein R.: Current status of grafts and implants in rhinoplasty: Part II. Homologous grafts and allogenic implants. Plastic and reconstructive surgery. Mar., 1; 125 (3): 99e-109e, 2010.

16- Cakmak O. and Ergin T.: The versatile autogenous costal cartilage graft in septorhinoplasty. Archives Facial Plast Surg., 4: 172-176, 2002.

17- Gerow F.J. and Stal S.: Keystone graft correction of the deviated nasal tip. Ann. Plast. Surg., 11 (4): 319-320, 1983.

18- Gunter J.P., Clark C.P., Friedman R.M., et al.: Dorsal augmentation: Autologous rib cartilage. In: Gunter J.P., et al. (eds) Dallas rhinoplasty (Nasal surgery by the masters). Quality Medical Publishing, St. Louis, pp 513$527,2002$.

19- Okazaki M., Sarukawa S. and Fukuda N.: A patient with congenital defect of nasal cartilaginous septal and vomeral bone reconstructed with costal cartilaginous graft. J. Craniofac. Surg., 16: 819-822, 2005.

20- Tardy M.E., Schwartz M.S. and Parras G.: Saddle nose deformity: Autogenous graft repair. Facial Plast. Surg., 6: 121-134, 1989.

21- Varadharajan K., Sethukumar P., Anwar M. and Patel K.: Complications associated with the use of autologous costal cartilage in rhinoplasty: A systematic review. Aesthetic Surgery Journal. Aug., 1; 35 (6): 644-52, 2015.

22- Otsuyanagi T., Mikami M., Yamauchi M., Higuam Y., Urushidate S. and Ezoe K.: A new technique for harvesting costal cartilage with minimum sacrifice at the donor site. J. Plast. Reconstr. Aesthet. Surg., 59: 352-359, 2006. 
23- Christophel J.J. and Hilger P.A.: Osseocartilaginous rib graft rhinoplasty: A stable, predictable technique for major dorsal reconstruction. Archives of facial plastic surgery. Mar., 21; 13 (2): 78-83, 2011.

24- Brent B.: The versatile cartilage autograft: Current trends in clinical transplantation. Clin. Plast. Surg., 6 (2): 163$180,1979$.

25- Gibson T. and Davis W.B.: The distortion of autologous cartilage grafts: Its cause and prevention. Br. J. Plast. Surg., 10: 257, 1951.

26- Fry H.: Nasal skeletal trauma and the interlocked stresses of the nasal septal cartilage. Br. J. Plast. Surg., 20: 146$58,1967$.

27- Kim D.W., Shah A.R. and Toriumi D.M.: Concentric and eccentric carved costal cartilage: A comparison of warping. Arch. Facial Plast. Surg., 8: 42-6, 2006. 